\title{
XXIV. On some phenomena of induced electric sparks
}

\section{S.P. Thompson B.A. B.Sc.}

To cite this article: S.P. Thompson B.A. B.Sc. (1876) XXIV. On some phenomena of induced electric sparks, Philosophical Magazine Series 5, 2:10, 191-198, DOI: 10.1080/14786447608639089

To link to this article: http://dx.doi.org/10.1080/14786447608639089

曲 Published online: 13 May 2009.

Submit your article to this journal $[\pi$

Џ Article views: 2

Q View related articles $₫$ 
On some Phenomena of Induced Electric Sparks.

passing through gross bodies. I have on several previous occasions treated of the problem of gravitating force theoretically, and by slow steps have approximated to its solution; but before the present attempt, I had not succeeded in exhibiting satisfactorily the rationale of this kind of attraction by vibrations.

26. In concluding this communication, I beg to call the attention of mathematicians to the different applications I have made of those laws of the mutual action of the parts of an elastic fluid which for brevity I call spontaneous vibrations. The mathematical theory of these vibrations I gave first in the Philosophical Magazine for May 1849; afterwards I applied them in accounting for the polarization of light in the undulatory theory (Philosophical Magaziue for December 1852, and 'Principles of Physics,' pp. 331-338); and in the present communication I have shown that they constitute an essential part of the a priori theory of music, and that it is necessary to introduce them in hydrodynamical theories of atomic repulsion and molecular attraction. Apart from the argument which I have elsewhere insisted upon, that these vibrations have been arrived at by logical deduction from the premises of hydrodynamics, the fact of their being capable of application in theories so various in kind and important in character as those above mentioned ought, I think, to be regarded as confirmatory of their truth.

Cambridge, July 22, 1876.

XXIV. On some Phenomena of Induced Electric Sparks. $B y$ S. P. Thompson, B.A., B.Sc.*

[Plate $\Pi$.].

1. THE observations communicated in this paper are the 1 result of an investigation into the phenomena discovered in November 1875, in Newark, N. J., by Messrs. T. A. Edison and C. Batchelor, and alleged to demonstrate the existence of a new form of energy. A detailed memoir of the phenomena has since appeared in the ' Quarterly Journal of Science 't, by Dr. G. M. Beard, of New York, who accepts, with some hesitation, the hypothesis of a new force.

2. When a galvanic current passing through the coils of an electromagnet is rapidly interrupted, minute bright sparks can, at the moment of interruption, be drawn from the electro-

* Communicated by the Physical Soeiety.

† "The newly-discovered Force," by George M. Beard, A.M., M.D., New York (Quarterly Journal of Science, No. L. April 1876). 
magnet-core by an earth-wire or by any conducting substance held in the hand and presented to the core*. These sparks are best seen when the electromagnet-coils, interrupter, and battery-cells are completely insulated from the ground. The substitution of a bar of any metallic substance, or even carbon or wood coated with tinfoil, in place of the iron core of the electromagnet, does not prevent the production of the spark. With bars of zinc or cadmium, or, better still, of either of these metals amalgamated on the surface, the sparks are brighter.

The minuteness of the sparks makes observation of them a matter of some difficulty; between two points of graphite pencils in a dark box they are more readily seen. They are conducted by all metallic bodies, and by the body; and even pass into insulated conductors of large surface, apparently requiring no completion of the circuit. This circumstance, however, as well as the supposed inability of the sparks to produce any indications upon the galvanometers and electroscopes of ordinary use, may be explained by a further knowledge of their nature. It was this apparent lack of polarity in the nature of the discharge that led to the adoption of the hypothesis of a new form of energy; and the assumption seemed further to be borne out by an apparent absence of physiological effect.

Two forms of the apparatus at first employed to produce the sparks in question are given in figs. $1 \& 2$. In the first case, where the circuit was rapidly interrupted by an automatic vibrator, the sparks were drawn from the electromagnetcore or from the vibrating armature. In the second they were drawn from a bar of metal placed above, but not in contact with, an electromagnet in a circuit completed by a depressor key.

3. Careful repetition of the experiments failed to elicit evidence of polarity in the spark, or to procure response to the ordinary electrical tests. And the wish to obtain further information upon the nature of this peculiar discharge by studying its effects in illuminating the rurefied gases of vacuum-tubes, rendered it necessary to seek a means of more plentiful production, and to abandon the methods of the original investigators already described; for the sparks so

* As an interrupter almost any form will answer; a Morse key is good for slow interruptions by hand; or an automatic vibrator, similar to the "break" of an induction-coil may be employed. Similar sparks have doubtless been often noticed by those who have used any form of apparatus involving rapid interruption of the current, and as often attributed to defective insulation. The writer of this paper observed the same thing some years ago in a trembler of particularly good construction, and in vain rewound the coils in hope of eliminating the supposed leak. 
obtained had never exceeded the quarter of a millimetre in length, and were quite incapable of producing a luminous discharge through a small vacuum-tube.

The following experiments led to the method desired:-

A rod of soft iron 20 centims. in length was wrapped in folds of vulcanized sheet rubber to a thickness of 2 centims. Around the exterior of this 150 centims. of stoutly insulated copper wire were wound. One end of this wire was connected with one terminal of the secondary wire of a small inductioncoil *, the other end was brought within 15 millims. of the other terminal. The intent of this arrangement was to pass, as in the previous experiments, an intermittent current around a metallic conductor. When the coil was set in action the secondary currents passed with rapid discharge across the interval of about 15 millims. between the end of the wire and the terminal; and it was then found that sparks of several millimetres length could be drawn from the iron rod within the folds of vulcanized rubber by an earth-wire, or by the finger, or by any conductor held in the hand. It was found impossible to convey any charge from the iron rod by a proofplane to an electroscope; and on leading a wire to a sensitive long-coil galvanometer by Colladon no deflection was obtained, though the sparks were drawn from the wire beyond the galvanometer, through which the force thus manifesting itself must therefore have passed. Identical effects followed the substitution of bars of copper, cadmium, and zinc for the iron rod.

It was next ascertained that no perceptible difference of potential existed between the two ends of the metal rod, and none between the ends and the median portion. The spark could be drawn indifferently at either end, or at the middle, but not from two points at once; nor could it be led by an insulated wire from one point of the bar to another. Other metallic objects in the neighbourhood of the bar became similarly affected; and from them sparks could be drawn. These effects were augmented when the distance of 15 millims. over which the secondary current of the coil discharged itself as a spark was increased to 20 millims. They diminished when the distance was reduced to 5 millims., and ceased entirely when the interval was reduced to nothing, so that the secondary current of the coil passed along unbroken metallic connexions. The conclusion to which these results pointed

* This coil, capable of throwing sparks of 50 millims. length with two cells of Grove's element, was employed in most of the succeeding experiments. Each piece of apparatus used, including the cells of the battery, was carefilly insulated from the table.

Phil. Mag. S. 5. Vol. 2. No. 10. Sept. 1876. 
was apparently that the effect was one of surface-charge. This surmise might be directly tested by increasing the size of the metallic core and the number of surrounding turns of wire.

4. The arrangement next to be described ${ }^{*}$, and shown in diagram at fig. 3 , was therefore directly suggested by the preceding experiments. It remained practically unchanged in the subsequent investigation. A large Leyden jar was taken and its inner and outer surfaces joined by a metallic wire, constituting it simply a conductor of large surface. Around it were wrapped sheets of vulcanized rubber to a thickness of 25 millims. About this again were coiled about 30 metres of stontly insulated copper wire $\dagger$. As before, one end of this wire was led to the terminal $T^{\prime}$ (fig. 3) - the other end, $w$, being placed near the terminal $\mathrm{T}$, and so adjusted that the distance $w \mathrm{~T}$ might be increased or diminished at will.

5 . When the coil was set in action, sparks could be drawn by an earth-wire, C, from the knob of the accumulator, Q. When the discharging-distance of the coil $w \mathrm{~T}$ was less than 5 millims., the sparks drawn from $Q$ were minute, not exceeding 1 millim. in length, destitute of perceptible physiological action, producing no deflection when led through an ordinary needle-galvanometer, and, as before, were incapable of imparting any charge to a proof-plane.

When $w$ was removed to a distance of 10 millims. from $T$ the sparks at $Q$ were larger and brighter; when the distance was increased to 20,25 , and 30 millims. successively, the sparks drawn at $Q$ were much more vivid and exceeded 10 millims. in length. These sparks, though producing comparatively little effect in contracting the muscles of the arm, were excessively painful and penetrating to the nerves of the skin. Their light was brightest when they passed between

* It will be plain, from the subsequent details, that this arrangement plays the part of an accumulator or condenser, the interior surface of which is represented by the Leyden jar, the exterior being represented by the wire coiled ontside. A Leyden jar is not essential; any cylindrical conductor is as good if of large surface; and a sheet of tinfoil laid upon the exterior of the insulating material is more effective than 50 metres of covered wire wound round it. The precise form of the accumulator is immaterial; but thorough insulation must be secured. The above arrangement is preferred because its parts are analogues of those of the experiments that suggested it. The knob of the jar is moreover convenient for drawing sparks from.

+ To avoid confusion, in fig. 3 the condenser arrangement is given in diagram, $D$ standing for the insulating folds of rubber, $P$ for one condensing surface (the external wire coils), $Q$ for the other condensing surface (the Leyden jar, which acts in this combination as if made of one piece of metal). 
poles of zinc, mercury, or carbon. Their brilliance was augmented and their length was increased to above 20 millims. when $w$ was withdrawn so far from $\mathrm{T}$ that only a faint brush discharge passed across from $v$ to $\mathrm{T}$, a distance of about 50 millims.; and a still greater effect was produced when $\mathrm{T}$ was directly connected with earth. This modification virtually changed the arrangement to that indicated in fig. $4^{*}$.

6. When the spark obtained between $Q$ and the earth-wire C exceeds 4 millims. in length, it is capable of illuminating a small vacuum-tube. The illumination differs, however, in a remarkable manner from that produced by the ordinary direct discharge of the induction-coil. Instead of the usual phenomena of a small brush of light at the positive pole, and a bright aureole or glow surrounding the negative pole, the illumination is symmetrical, alike at each pole, having both brush and glow at each, and is unaltered by reversing the primary circuit of the coil. An occasional flash, however, seemed to glow at one pole or at the other.

On making single contacts by holding the break-piece of the induction-coil in the fingers the effect was as follows:at each make-of-contact no illumination; at each break-ofcontact an illumination of the same symmetrical nature, affording no evidence of polarity of discharge in one direction more than in another.

7. To ascertain whether the discharge at the two poles was simultaneous or alternating, a rotating mirror was placed beside the vacuum-tube. The images were found to be, roughly speaking, alternate, the discharges being alternately from either pole. The irregularity of the alternation appeared to be dependent partly upon the distribution of the resistances in the circuit, partly upon the irregularities in the vibrations of the break. The occasional flashes of light at one pole or the other were explained by the occasional appearance in the mirror of two contiguous images having the same position, indicating the occurrence of two consecutive discharges in the same direction.

With rotating slits the same phenomenon of reciprocating discharge was observed, though less advantageously.

* Since the communication of these experiments to the Physical Society, my attention has been called to an article in the Journal of the Franklin Institute for June 1871, by Prof. E. J. Houston, of Philadelphia, where, under the title of "A New Connexion for the Induction-coil," he describes a somewhat similar arrangement, in which an insulated conductor is employed in connexion with the coil. With this combination Prof. Houston observed some curious effects of induction in neighbouring bodies; but he seems to have thought them due to escape of electricity, and apparently had no suspicion of the real nature of the sparks so produced. 
8. One terminal of a long-coil Thomson's reflecting galvanometer, by Elliott Bros., was put to earth, the other being connected with $Q$ (fig. 3). When the distance $w \mathrm{~T}$ was less than 5 millims. no deflection was produced upon the needle and mirror, a tremor being the only result. But when the distance $w \mathrm{~T}$ was gradually increased, and the secondary discharge had consequently to accumulate upon its conductors to acquire sufficient density to overleap the resistance of the increased thickness of air between $w$ and $\mathrm{T}$, the tremalous motion of the galvanometer-needle became much more marked, the spot of light wandering abont on either side the zero of the seale, never at rest, but showing no permanent deflection. When the distance $w \mathrm{~T}$ was increased to nearly 50 millims. the brisk flow of sparks gave place to the brush discharge, varied only by the passage of an occasional spark. In this case the wanderings of the spot of light on the scale were still more exaggerated, the needle apparently being turned little by little with an increasing deflection during some twenty or thirty vibrations of the contact-breaker of the coil, then receiving a sudden impetus in the opposite direction as the secondary spark discharged across the interval $w \mathrm{~T}$. This result was entirely confirmatory of the occasional flashes previously observed in the vacuum-tube, with which, on further examination, the more violent oscillations of the galvanometerneedle were found to be simultaneous. The experiment also accords with the previous observations of physicists with respect to the oscillations of the induced currents of the coil. It explains, too, why with an ordinary needle-galvanometer no deflection had been obtained with the minute sparks yielded by the earlier experiments.

9. Having again diminished the distance $w \mathrm{~T}$ to 5 millims., a wire was led from $Q$ to the knob of a gold-leaf electroscope. No divergence of the leaves took place; but on drawing sparks by the hand or by an earth-wire from the electroscope knob, from $Q$, or even from $T^{\prime}$, a divergence of the leaves took place, rapidly followed by collapse at every spark so drawn, the gold leaves being thrown into a state of violent flutter. If the hand, or earth-wire, were suddenly removed from contact, a residual charge usually remained upon the leaves of the electroscope ; and this charge was variously positive or negative, changing sign apparently according to the last oscillation of the secondary discharge.

Experimentation with the electroscope could not be carried on when $w$ was removed more than 10 or 12 millims. from T, as the momentary charges received by the gold leaves were so violent as to destroy them. 
10. Throughout the above experiments the most curious effects of induction were exhibited by all metallic bodies in the neighbourhood of the apparatus. From any of these within a range of several yards sparks of a similar reciprocating nature could be drawn by bringing near an earth-wire or any conductor of large surface, whether insulated or not.

11. It was found, as in a preceding case stated at the close of $\$ 3$, that no sparks could be drawn from $Q$ (fig. 3) when $w$ was brought up to actual contact with T. That is, an intermittent current (as is that in the secondary wire of the coil) passing through a closed circuit does not evoke that kind of disturbance in a neighbouring conductor which is evoked when the intermittent current has to overleap an interval of air, however short. This result proved that the appearance of a momentary charge upon $Q$ when $w$ and $T$ were separated was the result of induction from a momentary charge upon $P$, and not merely from a current passing through $P$. The wellknown phenomenon of the statical charge produced upon the separated terminals of the secondary circuit of an inductioncoil will account for the presence of single momentary charges upon $\mathrm{P}$ and upon $\mathrm{T}$. These charges must accumulate through a short but definite period of time until they have acquired sufficient density to overleap with a spark the resistance offered by the layer of air $w \mathrm{~T}$-the density of the accumulating charge depending on the dryness of the atmosphere, the perfectness of the insulation, and the distance between $v$ and T. Though this period be very short, such charges will necessarily, by the inductive influence of their presence, disturb the electrical equilibrium of all near conductors such as $Q$. The equally well-known phenomenon of the return-stroke, investigated by Lord Mahon in 1779, will account for the appearance of a return-spark after an interval perhaps not exceeding the thousandth part of a second, thus establishing the reciprocating nature of the discharges passing between $\mathrm{Q}$ and $\mathrm{C}$.

12. In the case of the earlier experiments $(\$ 2)$, where an interrupted primary current passes round an electromagnet, similar conditions virtually exist. The extra-current consequent on breaking the primary is a current of high electromotive force, like the secondary current of the coil. It, too, has a sensible interval to overleap, though the distance in this case is not constant. It, too, must accumulate upon its conductor in order to acquire sufficient density to overleap the gap in the circuit. It, too, can therefore, during a distinct minute period of time, analyze the neutral electricity of the electromagnet-core across the dielectric of silk or cotton that 
insulates the conducting wire therefrom. In this case, too, we have consequently the conditions of a rapidly charged and discharged condenser, giving rise to reciprocating induced sparks.

13. This conclusion can be directly proved by recurring to the earlier experiments (fig. 2) and introducing across the circuit a wire of suitable resistance to short-circuit the extracurrent so that it may complete its route without having to overleap the break at the key. This is shown in diagram in fig. 6 , where $R$ is a box of resistance-coils introduced between $a$ and $a^{\prime}$. If the wire of which the electromagnet $\mathrm{E}$ is made be stout, its resistance will be a mere trifle, and a resistance of 3 or $4 \mathrm{ohms}$ at $R$ will be sufficient. In some cases a drop of pure water between the points of contact at $K$ has also the result of obviating the extra-current spark. And in every case, when the conditions are so arranged as to obviate the appearance, on breaking contact, of the extra-current spark at $K$, no earth-wire, nor any conductor, will draw a spark from the electromagnet-core-a decisive proof that the sparks so drawn were due to indnction by the statical charge of the accumulating extra-current, and to that alone.

XXV. On the Nebular Hypothesis.-IV. Correlations of Central Force. By Puiny Earle Chase, LL.D., S.P.A.S., Professor of Philosophy in Haverford College.

[Continued from p. 36.]

THE various accordances of planetary mass and position 1 which have been pointed out in preceding papers, the harmonic prediction of a source of planetary disturbance at -269 Earth's radius vector which was confirmed by the sunspot observations of Messrs. De La Rue, Stewart, and Loewy, the comparison of gravitating and chemical force by means of the explosive energy of $\mathrm{H}_{2} \mathrm{O}$, the moasurement of gravitating waves, the agreement between the ratio of selenium-conductivity in sunlight to its conductivity in darkness and the ratio of Sun's light-emitting to its earth-attracting energies, and my various mechanical estimates of solar mass and distance seem to be dependent upon mathematical laws, among which the following merit special consideration.

Let $f=$ velocity communicable, at distance $r$, in time $t$, by any central force varying as $\frac{1}{d^{2}}$,

$f_{1}=$ velocity communicated by a single impulse, or in a single instant, 


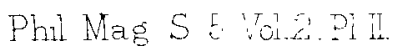

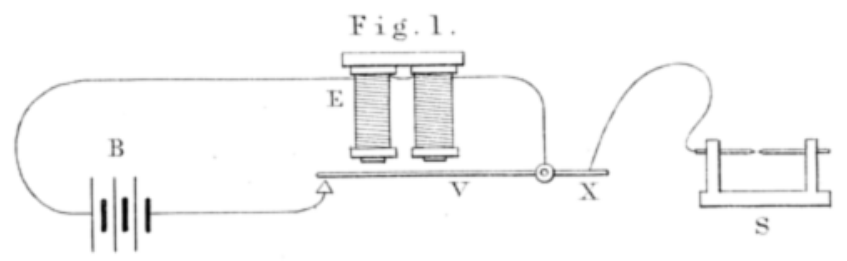

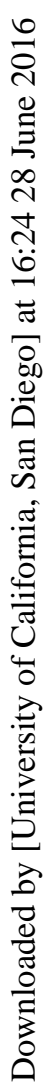
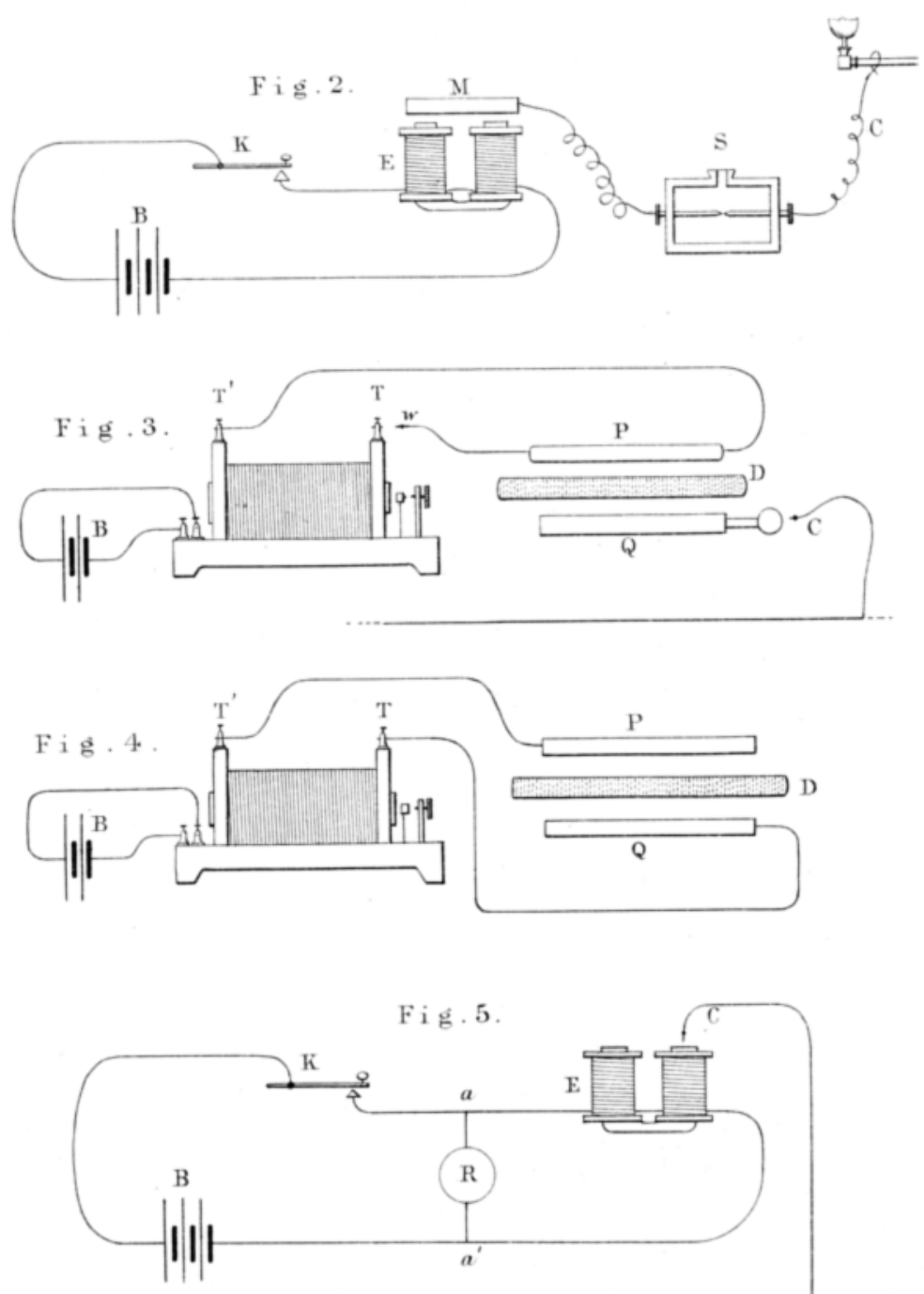